\title{
Research on the Satisfaction of Technological Innovation and Entrepreneurial Finance Policy
}

\author{
Hexuan Yu \\ Jilin University,Changchun,Jilin,130052 \\ 792052615@qq.com
}

\section{Keywords: Science and technology; Finance; Innovation and entrepreneurship; Satisfaction}

\begin{abstract}
At present, the government attaches great importance to and vigorously develops innovative and entrepreneurial economies and strives to build innovative countries. The country has a wealth of scientific and technological resources and strong scientific research strength, and has a decisive driving role in the development of innovative and entrepreneurial economies. To this end, a series of policies have been introduced in recent years to promote technological innovation and entrepreneurship. Among them, financial policies are directly related to the start-up and growth of technological innovation and entrepreneurship and the landing and implementation of outstanding projects. The formulation, implementation and feedback of financial policies play an important role in promoting technological innovation and entrepreneurship. This article aims to study the scientific and technological innovation and entrepreneurship financial environment, entrepreneurs' satisfaction with financial policies, key influencing factors, and the actual demands of entrepreneurs. Promote the rapid development of science and technology innovation and entrepreneurship in the financial environment, and provide strong support for various technology innovation companies.
\end{abstract}

\section{Introduction}

The revolution in information technology led to the rise of the Internet economy and also triggered a profound financial revolution. Internet science and technology innovation has infiltrated and profoundly influenced and changed various fields of economic and social development in an all-round and in-depth manner. The organic combination of the development of Internet science and technology innovation and finance has spawned internet finance based on satisfying the needs of wealth preservation and appreciation of the masses and the financing needs of vulnerable groups. Science and technology innovation and venture capital increase the efficiency of capital financing, promote the process of inclusive finance, and become a useful supplement to the existing financial system. Under the conditions of scientific and technological innovation and entrepreneurship, the financial industry is in a state of brutal growth, and various risk issues have become increasingly prominent. Strengthening risk prevention and supervision has become a practical need to promote the sustainable and healthy development of science and technology innovation and business finance and maintain the security and stability of the financial system. This article analyzes the financial environment for technological innovation and entrepreneurship, then evaluates entrepreneurs' degree of concern and satisfaction with various indicators of financial policy, and uses the quadrant quadrant chart method to find key influencing factors, aiming to study the scientific and technological innovation and entrepreneurship financial environment and entrepreneurs' Satisfaction of financial policies, key influence factors, and actual demands of entrepreneurs.

\section{Evaluation of Technological Innovation and Entrepreneurship Financial Policies}

The science and technology innovation and entrepreneurship financial policy evaluation refers to the science and rationality of the science and technology innovation and entrepreneurship financial policy and the evaluation of its operation and implementation. According to the research content of the existing literature, combing from the three aspects of evaluation of science and technology 
innovation and entrepreneurship financial policy system, evaluation of science and technology innovation and entrepreneurial finance and taxation policy, and evaluation of technological innovation and venture capital market policy.

The evaluation of technological innovation and entrepreneurship financial policy system integrates the interaction and interaction of market policy, science and technology financial service policy, and science and technology innovation and entrepreneurship finance and taxation policy. The existing research on the evaluation of technological innovation and entrepreneurship financial policy system mainly focuses on two aspects: the implementation of policy arrangements and policy systems.

Evaluation of science, technology, finance and taxation policies

In recent years, China has formulated a number of fiscal and taxation financial policies to support technological innovation and development policies, and adopted a variety of support methods, such as subsidies, interest subsidies, guarantees, tax incentives, etc. This article reviews the policies. (1) Financial Subsidy Policy. As the outcome of scientific and technological innovation has a positive externality, the government provides compensation and incentives through financial subsidies. The existing literature analyzes the role of innovation from different financial subsidies and factors that affect the efficiency of subsidies. (2) Tax policy. Tax policy refers to the taxation policies related to technological innovations such as tax incentives and tax reductions that the state has given to promote technological innovation.

Evaluation of science and technology financial market policy

Risk investment is the most important equity financing channel before technology-based enterprises are listed and financed. However, there are many problems in China's existing scientific and technological venture capital investment, and the implementation effect is not good. China's science and technology venture capital investment policy has a guiding role in investing venture capital into high-tech fields, and has a positive correlation with the scale of investment in high-tech fields, but government venture capital investment is not effective.

\section{The Problems Existing in Science and Technology Innovation and Entrepreneurship Financial Policies}

Lack of scientific and technological innovation and entrepreneurship financial core goals, resulting in lack of synergy in technological innovation and entrepreneurship financial policies

The current technological innovation and entrepreneurship financial policy lacks the core goals of science and technology innovation and entrepreneurship finance, resulting in a lack of joint efforts in science and technology innovation and entrepreneurship financial policies. The overall goal of the development of science and technology is proposed, but it also does not involve technological innovation and entrepreneurship finance. At the same time, the policies directly based on science and technology innovation and venture capital appear in the form of opinions, lacking policies at the legal and regulatory levels, and mainly involve the further improvement of various technological innovation and entrepreneurship financial instruments.

The technological innovation and entrepreneurship financial environment policy is not perfect, leading to high risk of technological innovation and entrepreneurship finance

The technological innovation and entrepreneurship financial environment is the economic, social, legal, cultural and other systems, systems, and traditional environments in which science and technology innovation and entrepreneurship financial instruments operate. It mainly includes information disclosure systems, credit systems, intermediary service systems, property rights systems, and integrity and innovation. Cultural systems, technology guarantees, technology insurance, and financial science and technology inputs. Good science and technology innovation and entrepreneurial financial environment can reduce the cost of information collection between science and technology enterprises and financial institutions, which is conducive to the resolution of information asymmetry problems, can effectively reduce technological innovation and entrepreneurial financial risks, and achieve deep integration between science and technology and finance. Important role. However, the existing technological innovation and entrepreneurial 
financial environment policies are not perfect, leading to high risks of technological innovation and entrepreneurship finance. The state has issued some policies on science and technology guarantees, science and technology insurance, and intellectual property rights, but there are few policies on the establishment of information, credit, and cultural systems.

The policy of technological innovation, entrepreneurship and financial marketization is not perfect, resulting in insufficient financial support.

Financial markets are of particular importance for promoting independent innovation and technological advancement and effectively managing the risks of the economic system. However, the current market-oriented policies for technological innovation and entrepreneurship finance are not perfect, reducing the benefits of financial support and resulting in insufficient financial support. The value-added protection of state-owned assets has, to a certain extent, reduced the driving force for financial support. Therefore, in the face of the high risks and long-term benefits of technology-based companies, especially the seed and start-up stages of SMEs, state-owned policy banks generally have a "credit" phenomenon when starting science and technology loan business. Institutions tend to invest capital in mature technology companies, rather than seed and start-up periods. The excessive government regulation of financial market prices has led to an imbalance between government and market mechanisms. Take science and technology loans as an example, the loan interest rates of commercial banks in China have not been fully marketized. China's commercial banks can only implement interest rates in accordance with the policies stipulated by the Central Bank, and they cannot independently set prices, leading to insufficient incentives for banks to use science and technology loans. In fact, the insurance premium rates for technology insurance also face the same problem.

\section{The Three Economic Effects of Science and Technology Financial Activities}

\section{External network economic effects}

The root of the existence of network externalities in network activities lies in the systemic nature of the network and the interactivity of internal information flows. First of all, no matter how many new outlets are added, it will become part of the Internet and will be integrated with the original network. Therefore, the entire network will benefit from the expansion of the network. Secondly, in the network system, the information flow is not unidirectional, and any two nodes in the network can communicate with each other, which ensures the universal significance of the external economy. Many scholars have conducted in-depth research on network externalities. Network finance, as a financial activity based on the Internet, naturally embodies this economic law. Network externality refers to the existence of such products. The utility of a user to consume such a product increases as the number of consumers who consume the same product increases.

Scale economy effect

Economies of scale refer to the fact that the average cost of producing a single unit or composite product is declining in a certain interval under the established technical conditions. Because the traditional economy is mainly based on scarce natural resources, the production of material information. Therefore, in the traditional economic theory, the economic utility of production scale will generally go through three stages of increasing scale returns, constant returns to scale, and decreasing returns to scale. The cost curve is U-shaped. The reduction of dependence on physical resources in the network economic activities makes the constraints of scarcity of natural resources no longer exist. Therefore, this traditional theory has not been applied to network economic activities. Network economy is an economy with increasing marginal revenue. Correspondingly, when the scale of online financial services continues to expand, it will only appear as two stages of increasing scale returns without the same scale returns and diminishing returns. The scale economy of online finance means that when the scale of online financial services expands, the unit cost of a particular financial service, such as deposits, loans, or all businesses, will decline, and the revenue will increase.

The scope of economic effects

The scope economy effect refers to the reduction of unit cost caused by the production of two or 
more products (not just one product). The scope economic effect of network finance refers to the synergy effect that financial institutions produce a variety of financial products through the coordinated use of input factors, resulting in cost savings. Network finance not only makes great changes in the financial industry service measures, but also embodies the convenience of integrated services in the financial services industry, and can provide various portfolio financial product services. Since the network financial services rely mainly on information, knowledge and networks, the sharing of these soft elements makes the network financial services have a scope economic effect.

\section{Evaluation of Innovation and Entrepreneurship Financial Policy Satisfaction and Vision}

According to the fuzzy comprehensive evaluation method, this paper adopts the Likert four-scale scale, and it is calculated that the degree of satisfaction of entrepreneurs with innovation and entrepreneurship financial policies is 2.849 , which is a general level. Specifically analyze the degree of satisfaction with various indicators of financial policies and the main focus of the government. There is no extreme situation where the surveyed indicators are too wide apart from the expectations of entrepreneurs. However, different indicators need to be treated differently by the government.

Set multiple-choice questions to find innovative entrepreneurs' direct demands on financial policies in order to interface with the analysis and research results of the previous data, and finally put forward effective and effective countermeasures and suggestions for the improvement and perfection of innovation and entrepreneurial financial policies so that policies can be put in place. .

Entrepreneurs believe that diversification of the guarantee mechanism, diversification of financing channels, and addition of new loan types are the primary measures for the bank's competent department to solve the current corporate financing difficulties. This shows that financial development is characterized by a pattern of supply less than demand and imbalance between supply and demand. In a sound and favorable internal and external environment, financial concept innovation, institutional innovation, business model innovation, product and service innovation, management innovation, and risk prevention innovation are all imperative.

In the solution to corporate financing difficulties, the establishment of a financial institution dedicated to lending to small enterprises, the establishment of a credit rating system for small enterprises, and the promotion of a new type of popularization of "mobility" pledges have been considered the most important and most needed solutions by entrepreneurs.

Most entrepreneurs hope that the government will speed up the development of the technology-based SME capital market, encourage the development of venture capital industry, and further establish and improve the system of small and medium-sized financial institutions. This shows that technology-based companies do not aspire to directly obtain subsidies and concessions from the government, but rather long for the government to build and create a sound financing environment and formulate sound operating rules. If the aforesaid appeals can be valued and implemented, it can greatly ease the financing difficulties of SMEs, and at the same time, it can also realize the long-term mechanism of financing normalization, institutionalization, standardization and risk prevention.

\section{Conclusion}

This article analyzes the scientific and technological innovation and entrepreneurship financial environment from the macro level; from the perspective of policy data, it uses the four-quadrant chart of key factors to conduct an in-depth analysis of financial policy satisfaction and its influencing factors; finally, from the perspective of entrepreneurs, it studies the technology Direct demand for innovative and entrepreneurial financial policies. As a result, it has been found that technological innovation entrepreneurs are generally satisfied with science and technology innovation and entrepreneurship financial policies, narrow financing channels, single financial products, and conservative financial models are the main problems that restrict technological 
innovation and entrepreneurship.

\section{References}

[1] Amorós J E 1. Ten Years of Global Entrepreneurship Monitor: Accomplishments and Prospects[J]. International Journal of Entrepreneurial Venturing, 2013, 5(5):120-152.

[2] Andries P, Czarnitzki D. Small firm innovation performance and employee involvement[J]. Small Business Economics, 2014, 43(1):21-38.

[3] Nanda R, Rhodes-Kropf M. Investment cycles and startup innovation $\hat{z}[\mathrm{~J}]$. Journal of Financial Economics, 2013, 110(2):403-418.

[4] Min-Feng L U, Yang L. Research on Strategy of Internet Financial to Drive Innovation and Development of Real Economy[J]. Journal of Hunan Finance \& Economics University, 2015.

[5] Certo S T, Holcomb T R, Holmes R M. IPO Research in Management and Entrepreneurship: Moving the Agenda Forward[J]. Social Science Electronic Publishing, 2015, 35(6):1340-1378.

[6] Hendricksona L, Bucifala S, Balaguera A, et al. The employment dynamics of Australian entrepreneurship[J]. 2015.

[7] Reisach U. The creation of meaning and critical ethical reflection in operational research[J]. Euro Journal on Decision Processes, 2016, 4(1-2):5-32.

[8] Jiang X. A Study on Innovation and Entrepreneurship Education Mode of Local Universities of Finance and Economics under the "Double First-rate" Strategy[J]. Journal of Nanchang Normal University, 2017.

[9] Miao Y U. The fusion of Internet+ and innovation and entrepreneurship education in applied universities[J]. Journal of Changchun Institute of Technology, 2017.

[10] Xia S, Liu Y, Wang J, et al. Design and Implementation of Innovation and Entrepreneurship Service Platform for Scientific and Technological Workers Based on PHP $[\mathrm{J}]$. Computer \& Telecommunication, 2015.

[11] HUANG Sai-li, Putian University. The Difficulties and Breakthrough of Innovation and Entrepreneurship Education of Local University[J]. Journal of Hunan City University(Natural Science), 2016.

[12] LI Yong, et al. "Research on the Role of Internet in Innovation and Entrepreneurship Education." Modern Computer (2017).

[13] ZHANG Ting, and YANG Yanfei. "On the Development Mode and Implementation Path of Education Innovation and Entrepreneurship of College Students." Pioneering with Science \& Technology Monthly(2018).

[14] Qiao P. Research on the Nature of Return to Finance,Internet Financial Innovation and "e Rent Treasure"[J]. Theory \& Practice of Finance \& Economics, 2018. 